\title{
Menstrual function in sports
}

\author{
Nikolaos D. Roupas, Neoklis A. Georgopoulos \\ Department of Obstetrics and Gynecology, Division of Reproductive Endocrinology, Patras University Medical School, \\ Patras, Greece
}

\begin{abstract}
OBJECTIVE: To highlight the recent developments in the field of menstrual function in sports and to provide an overview of our current understanding in regard to the pathophysiology, evaluation and management strategies of exercise-related reproductive dysfunction. DESIGN: A PUBMED search was carried out and all articles published from 1980 to 2010 with title words related to exercise, athletes, menstrual function and primary and secondary amenorrhea were reviewed. The review structure includes a pathophysiology overview, menstrual dysfunction among different athletic disciplines, clinical manifestations, evaluation and management strategies, with particular emphasis on recent data regarding the use of oral contraceptives and hormone replacement therapy. RESULTS AND CONCLUSION: Exercise-related reproductive dysfunction appears to be multifactorial in origin and remains a diagnosis of exclusion. Recent findings underscore the endocrine role of adipose tissue in the regulation of metabolism and reproduction, providing further data on our understanding of the pathophysiology of exerciserelated reproductive dysfunction. Clinical manifestations range from primary amenorrhea or delayed menarche to luteal phase deficiency, oligomenorrhea, anovulation and secondary amenorrhea. Amenorrhea constitutes the most serious clinical consequence and is associated with bone pathology. Early diagnosis, thorough evaluation and individualized management (ranging from diet and exercise, or behavior adjustments to pharmacologic treatment) should be achieved in order to preserve bone mass.
\end{abstract}

Key words: Artistic gymnast, Athlete, Gymnast, Menstrual function, Primary amenorrhea, Pubertal development, Reproductive function, Rhythmic gymnast, Secondary amenorrhea

\section{INTRODUCTION}

Over the past three decades, major social changes have fostered the development of a positive attitude

\footnotetext{
Address for correspondence:

Neoklis A. Georgopoulos, Department of Obstetrics and Gynecology, Division of Reproductive Endocrinology, University of Patras Medical School, University Hospital, 26500 Patras, Greece, Tel.: +302610999835,

Fax: +302610993854, e-mail: neoklisg@hol.gr

Received 31-08-10, Revised 01-12-10, Accepted 10-01-11
}

towards physical exercise in general and, in female athletic activities in particular. Thus, women are becoming increasingly involved in physical activities, ranging from regular mild exercise to highly competitive performance requiring intensive and strenuous training.

The beneficial role of exercise in the promotion of both mental and physical health is indisputable. However, as the current general trend is towards 
considerable increase in the duration, frequency and intensity of exercise, great concern is arising with regard to the deleterious effects of intensive physical exercise on somatic growth and biological maturation.

This review aims at providing an overview of our current understanding of the effect of exercise on reproductive function and bone metabolism, including evaluation and management strategies of related pathology.

Individual sports exert a unique impact on body composition and development each depending on the sport-related specific features, technical skills and training methods and the state of growth and maturation of the athlete at exercise initiation and later on. These influences have been studied in females of all ages engaged in highly competitive sports, including gymnastics, endurance running, swimming and ballet dancing.

It is well documented that the female reproductive system is highly sensitive to changes regarding both intrinsic and extrinsic factors. Thus, female athletes exposed to intensive training and associated psychological stress as well as to strict dietary restraints are prone to developing reproductive dysfunction and bone pathology.

\section{EXERCISE AND REPRODUCTIVE DYSFUNCTION}

\section{Prevalence}

Abnormalities of the reproductive system are encountered in 6-79\% of females involved in sports activities. ${ }^{1}$ It is well documented that female athletes involved in a wide variety of sports, including runners, swimmers, tennis players, ballet dancers and gymnasts, present delayed menarche. ${ }^{2-6}$ The prevalence of menstrual dysfunction has been studied widely and varies with the specific sport and the level of competition. ${ }^{1}$

Based upon specific sport-related features, including training methods and technical skills, sports could be classified into the following categories: technical, endurance, aesthetics, weight class, ball game, power and anti-gravitation sports. Moreover, athletic events may be further grouped into 'leanness and nonleanness' on the basis of the optimal somatotype for each specific sport.?

\section{CLINICAL PATTERNS OF EXERCISE-RELATED MENSTRUAL ABNORMALITIES}

Menstruation represents a particularly delicate function and its regularity reflects normal reproductive activity. Normal interplay between the hypothalamus, pituitary, ovaries and endometrium give rise to predictable cyclic menses that signify regular ovulation. Ovarian function and menstrual regularity depend on normal cyclic pituitary gonadotropin stimulation. The secretion of gonadotropins occurs in response to pulsatile gonadotropin-releasing hormone $(\mathrm{GnRH})$ release from the hypothalamus which is regulated by various neurotransmitters and neuropeptides.

Female athletic performance has been associated with a broad spectrum of menstrual dysfunction, ranging from primary amenorrhea or delayed menarche to luteal phase deficiency, oligomenorrhea, anovulation and secondary amenorrhea.

The term amenorrhea refers to the absence of menses. The reproductive dysfunction in amenorrhea is characterized by infrequent or absent luteinizing hormone (LH) pulses accompanied by suppressed follicular development, ovulation and luteal activity, leading to persistently low levels of estrogens and progesterone and absence of endometrial proliferation. ${ }^{8}$ Primary amenorrhea is diagnosed when there has been a failure to menstruate by the age of 15 years in the presence of normal secondary sexual characteristics, or within five years after breast development if this occurs before the age of $10 .{ }^{9}$ Secondary amenorrhea is defined as the absence of three or more consecutive menstrual cycles following menarche, while oligomenorrhea describes menstrual cycles longer than 35 days or menstrual intervals of 45 to 90 days.

Luteal phase deficiency denotes asymptomatic subclinical menstrual disturbances resulting in low estradiol levels in the early follicular phase and decreased but normal LH pulse frequency with increased pulse amplitude. Although ovulation occurs, the developed corpus luteum produces reduced progesterone support for adequate endometrial development in the secretory phase. Thus, successful implantation of the fertilized egg is prevented and infertility ensues.

Anovulation is a more severe asymptomatic reproductive dysfunction characterized by suppressed follicular maturation leading to lack of ovulation. Both 
estrogen and progesterone levels are low, but some proliferation of endometrium is achieved resulting in profuse bleeding at irregular intervals.

\section{PATHOPHYSIOLOGY OF EXERCISE-RELATED MENSTRUAL ABNORMALITIES}

During the last three decades numerous studies have been conducted in regard to sports activities and athletic performance with emphasis on the influence of physical activity on reproductive function. The main factors related to menstrual disturbances in athletes are weight, body composition, stress (physical and psychological), energy imbalance, diet, type of sport and the state of reproductive maturity.

\section{Weight and body composition}

One of the earliest and most interesting observation on menstrual dysfunction in athletes was made by Frisch RE et al (1974) who theorized that the onset of menarche is achieved when body fat reaches a "critical threshold", namely $17 \%$ of body weight and that menstruation is disturbed when body fat falls below the "critical threshold" of $22 \%$ of body weight. According to Frisch's theory, at a critical percentage of body fat the metabolic rate decreases and the sensitivity of the hypothalamus to gonadal steroids is altered.$^{10}$ On the basis of these early observations, low weight and altered body composition have been considered the most cogent explanation for female reproductive dysfunction occurring in athletes. Recent studies however have challenged the theory that menstruation depends upon a critical body weight or fat percentage..$^{11-13}$

Attention is being increasingly focused on the role of adipose tissue as an active endocrine organ. Pertinent studies have revealed a number of adipocytessecreted factors (known as adipokines) which are involved in signalling, energy balance, insulin action, reproductive function and inflammation processes. Among the adipokines, leptin has a prominent role in reproductive function, while adiponectin is attracting increasing interest as a mediator in metabolism and reproduction.

The discovery of leptin however boosted scientific interest in the body composition hypothesis. Leptin has been considered as a link between the adipocyte and the reproductive system ${ }^{14}$ and has been considered to play a pivotal role in mediating a metabolic interaction between body fat and reproductive function. Serum leptin levels reflect the dietary status and caloric balance. Thus, rapid and profound decline in leptin levels has been documented in response to fasting and dietary restrictions, while extreme increases have been noted in response to overfeeding and refeeding following caloric deprivation. It has however been reported that even in severely undernourished women, the neuroendocrine control of reproductive function is preserved and is mediated by leptin. ${ }^{15}$ This strongly suggests that a critical level of leptin is required for the maturation and maintenance of menstruation. ${ }^{16} \mathrm{It}$ has also been reported that serum leptin levels were reduced in highly trained athletes and the diurnal pattern of leptin secretion was lost in amenorrheic but not in menstruating athletes. ${ }^{17}$

Adiponectin is markedly reduced in obesity and rises with prolonged fasting and significant weight reduction. Besides a well-described role in metabolism, cardiovascular protection and inflammatory process, recent studies suggest a potential role for adiponectin in the regulation of neuroendocrine reproductive processes. Specifically, it has been reported that adiponectin inhibits both basal and GnRHstimulated LH secretion in short-term treated rat pituitary cells. ${ }^{18}$ Furthermore, Lu et al reported that in $\mathrm{L}$ beta $\mathrm{T} 2$ mice cells, adiponectin acutely reduced basal and GnRH-stimulated LH secretion but had no effect on FSH levels. ${ }^{19}$ Thus, adiponectin could be considered as a link between adipocyte and the reproductive system. Consequently, high levels of adiponectin (as found in lean and energy restrained female athletes) may contribute to the suppression of LH levels and chronic anovulation.

\section{Physical stress}

The hypothesis that menstrual disturbances in athletes might be caused by the stress of exercise was originally based on animal experiments and has recently been supported by studies in amenorrheic athletes. Studies on the interaction between the hypothalamic-pituitary-adrenal (HPA) axis and the reproductive system carried out in rats and monkeys $\mathrm{s}^{20,21}$ demonstrated that alterations in the hormones of the HPA axis could disrupt the reproductive function via both central and peripheral effects. ${ }^{22}$ 
Bullen et al reported that untrained, regularly menstruating women developed menstrual disorders when exposed to strenuous exercise. ${ }^{23}$ Specifically, regularly menstruating, untrained women when exposed to high volume aerobic exercise, presented increased prevalence of luteal phase deficiency and anovulation. Moreover, a mild degree of cortisol increase has been documented in amenorrheic athletes. In general, athletes presenting profound menstrual disorders exhibit a greater activation of the HPA axis. ${ }^{8,22,24}$ It is thus evident that activation of the HPA axis represents an endocrinologic mechanism of reproductive dysfunction in female athletes. Cortisol can suppress gonadotropin secretion from the pituitary, 25 while corticotropin-releasing hormone $(\mathrm{CRH})$ can suppress GnRH secretion from the hypothalamus by increasing the hypothalamic opiate inhibition. ${ }^{26}$

\section{Psychological stress}

Psychological stress is another factor commonly implicated in the etiology and pathogenesis of exercise related menstrual disturbances. Although there are studies correlating behavioral and psychological parameters in women with functional hypothalamic amenorrhea, few data exist to support this hypothesis in athletes. ${ }^{27}$ Amenorrheic athletes exhibit a similar psychological profile compared with menstruating athletes. ${ }^{28}$ In addition, studies among musicians whose lifestyle is similarly competitive to that of athletes have shown that the psychological stress of competitions has no causative role in the reproductive dysfunction of most individuals. ${ }^{3}$

\section{Energy availability}

Recent studies have implicated energy availability (defined as dietary energy input minus exercise induced energy expenditure) rather than body weight or exercise stress in the pathogenesis of reproductive dysfunction in female athletes. ${ }^{13}$ It has been proposed that negative energy balance (failure to meet the metabolic requirements) causes an alteration in brain function that disrupts the GnRH pulse generator through an as yet unknown mechanism.

Researchers studying monkeys concluded that exercise-induced amenorrhea was reversed by diet and caloric supplementation, without any modification in their exercise regimen. ${ }^{29}$ It appears that energy depletion leads to a suppression in LH pulsatility regardless of the cause. It has been shown that caloric imbalance prevents the normal pulsatile secretion of $\mathrm{LH}$ in exercising women. ${ }^{30}$ Thus, it is proposed that exercise per se has no detrimental effects on female reproductive regulation, apart from that resulting from impaired energy balance.

\section{Diet}

Few data exist regarding a possible role of diet composition on the pathogenesis of menstrual disorders in athletes. Apart from the influence of reduced caloric intake (i.e. insufficient to compensate for the increased energy expenditure), the effect of diet composition per se on reproductive function in female athletes has also been studied. Protein and fat intake appears to be decreased in amenorrheic athletes. Data from studies attempting to correlate the incidence of menstrual disorders with different types of diets (in particular vegetarian diets, favored by some athletes) have been controversial. ${ }^{31.32}$ Therefore, the effect of different types of diet on reproductive function cannot be assessed without considering the synergistic effect of other factors such as energy balance, training intensity or emotional stress.

\section{Training methods/Sports characteristics}

It is well known that the unique character of each sport is determined by the specific skills requirements, appropriate somatotype and special training methods. The age of training onset, the somatotype, the specific sports demands as well as the intensity, frequency and duration of training impose dietary restrictions and a certain energy and metabolic profile, all of which are highly likely to influence the menstrual status of female athletes.

A heavy training load appears to exert more harmful effects on menstrual function when initiated abruptly compared with a gradual acceleration. ${ }^{33}$ Moreover, long-term training at levels of energy expenditure above the lactate threshold affects menstrual function more than long-term training at or below the lactate threshold. ${ }^{34}$ Furthermore, exercise-related menstrual disorders are more common among endurance runners and ballet dancers than in swimmers and cyclists. ${ }^{6,35,36}$ This fact could be attributed to the specific optimal somatotype demands, namely attracting individuals of certain body characteristics according to the types of elite competitive sports (e.g. 
thinness in ballet dancers and long-distance runners) combined with dietary adaptations and restrictions.

\section{Reproductive maturity}

It has been suggested that intense training has less effect on the menstrual function of previously sedentary, menstruating individuals compared with those of premenarcheal adolescents. ${ }^{37}$ This might be due to the fact that reproductively immature females are more sensitive to the detrimental effects of strenuous exercise. Nevertheless, any attempt to isolate reproductive maturity as a factor interfering in the pathogenesis of exercise-related reproductive dysfunction and to evaluate this separately from energy availability, body fat and body weight is not an easy task. ${ }^{13}$

\section{MENSTRUAL DISORDERS IN SPECIFIC SPORTS}

Somatic growth and pubertal development in runners have been extensively studied, incorporating precise categorizations. For example, despite competing in the same field of sport, runners are divided into recreational, small-distance and long distance, this based on the training methods, the technical skills, the favorable somatotype and the specific requirements for each event. Other categorizations are more clear-cut. For instance, athletes participating in power events (e.g. sprints, hurdles) train at maximal or near-maximal intensity in short bursts, while athletes participating in endurance events (e.g. middle-distance and distance running) train at lower intensity levels for extended periods. Power athletes are heavier and have more total lean mass than their endurance counterparts. ${ }^{39}$

Menstrual disorders occur in $24-26 \%$ of runners. ${ }^{40,41}$ In distance runners, the prevalence of amenorrhea increases from $3 \%$ to $60 \%$ as training distance increases from $<13$ to $>113 \mathrm{~km}$ per week, while their body weight decreases from $>60$ to $<50 \mathrm{~kg} .{ }^{36}$ Furthermore, subclinical menstrual disorders are found in both highly trained ${ }^{8}$ and recreational ${ }^{42}$ eumenorrheic athletes; luteal deficiency or anovulation was found in $78 \%$ of eumenorrheic recreational runners in at least one out of three menstrual cycles. ${ }^{42} \mathrm{On}$ the other hand, in sub-elite, moderately exercising female runners, no effect on pubertal development was demonstrated. ${ }^{43}$
Dance training has been shown to be associated with a high incidence of menstrual dysfunction, particularly in disciplines such as ballet. ${ }^{35}$ Ballet dancers begin strenuous training at an early age while undergoing intensive exercise and heavy caloric restrictions (this leading to energy deficit) in order to perform at a competitive level and retain a lean physique. Teenage ballet dancers are lighter with less body fat, this typically accompanied by a higher incidence of delayed puberty and primary or secondary amenorrhea, compared with less physically active girls. ${ }^{33,35}$

Swimmers present normal weight, less fat and more muscle mass than nonathletic girls, but a greater percentage of fat than that of amenorrheic athletes in other sports. ${ }^{3}$ The latter reflects an adjustment to the sport-specific requirements, as in aquatic sports subcutaneous fat helps floatation, reducing energy expenditure for water surface maintenance. Constantini et al studied swimmers of competitive level and demonstrated that menstrual cycles were irregular or anovulatory rather than absent. Considering the greater amount of fat in swimmers, that functions as an estrogen producer and reservoir, the observed menstrual disturbances may not be attributable to hypoestrogenism but might instead be due to mild hyperandrogenism. ${ }^{44}$

In gymnastics, in the case of gymnasts performing at the high competitive level of e.g. the Olympic Games, a delayed menarche has been noted compared to high school, college and club-level athletes. ${ }^{45}$ Furthermore, young girls or adolescents engaged in sports requiring training $<15$ hours per week less frequently have menstrual disturbances or delayed sexual maturation. ${ }^{45}$ Serial studies in high-level gymnasts demonstrated that in both elite rhythmic gymnasts (RG) and artistic gymnasts (AG), the prepubertal stage was prolonged and pubertal development was shifted to a later age, retaining a normal progression rate and following the bone age rather than the chronological age. ${ }^{46-51}$ It is to be underlined that for both RG and AG, pubertal progression, although delayed, was not prolonged. Normal girls require an average of $1.96 \pm 0.93$ years (mean $\pm \mathrm{SD}$ ) for their breast development to progress from Tanner stage II to Tanner stage IV. ${ }^{52}$ A comparable period of time was observed for both $\mathrm{RG}$ and AG. Therefore, pubertal maturation is entirely shifted to a later age while maintaining a normal rate 
of progression. Furthermore, in RG, menarche was significantly delayed compared to their mothers and non-trained sisters, an observation arguing against a genetic predisposition towards delayed menarche. ${ }^{48}$ Therefore, in RG and AG, intensive physical training and negative energy balance prolong the prepubertal stage and delay pubertal onset by regulating the hypothalamic pituitary set point of puberty without however affecting the duration of the pubertal process.

\section{CLINICAL CONSEQUENCES}

\section{Short-term}

Exercising women experience short-term infertility due to anovulation, which however is reversed after termination of exercise. Chronic anovulation may lead to profuse bleeding at unexpected times, which can vary from a mild inconvenience to significant blood loss requiring hospitalization.

\section{Long-term}

The deleterious effects of exercise-induced reproductive dysfunction are caused by the lack of estrogens action. It is well known that estrogens profoundly affect the urogenital epithelial maturation, the cardiovascular system and bone health.

\section{Urogenital disturbances}

Estrogens promote maturation of the urogenital epithelium and maintain a thick vaginal epithelium that is resistant to various disorders. By contrast, a hypoestrogenic status leads to the development of a thin vaginal epithelium, which may lead to atrophic urethritis and vaginitis. However, since estrogen deficiency of several years is necessary for the development of urogenital atrophy, this condition is uncommon among female athletes considering that only a small proportion of them remain severely hypoestrogenic for a long period.

\section{Cardiovascular risk}

It has been reported that estrogen deficiency impairs endothelium-dependent vasodilation in amenorrheic athletes. ${ }^{53}$ Furthermore, it has been noted that amenorrhea in young endurance athletes is associated with endothelial dysfunction and unfavorable lipid profile as well as other risk factors for atherosclerosis. ${ }^{54}$

\section{Effects on bones}

Exercise-associated menstrual dysfunction and the consequent estrogen deficiency have a profound impact on the skeleton. Failure to reach peak bone mass, bone loss and inadequate bone mineralization predispose hypoestrogenic athletes to osteopenia and osteoporosis and to increased risk of scoliosis and bone fracture. ${ }^{1}$ Although genetic factors considerably influence bone mass, other factors such as nutrition, physical exercise, various diseases, drugs, age at menarche and ovarian function regulate the acquisition of bone mass in a moderately synergistic action. According to De Souza et al, female athletes experiencing both energy and estrogen deficiency present a worse bone turnover profile compared to athletes with only one or none of these abnormalities. ${ }^{55}$

There is general agreement that physical activity enhances bone formation and, consequently, increases bone mineral density (BMD).$^{56}$ The higher strain levels, associated with extreme physical activity increase bone mass by inducing accretion on bone surfaces.

Bone mass doubles between the onset of puberty and early adult life.$^{57}$ Sex steroids are responsible for the maturation and increase of the human skeleton after the onset of puberty. Recent data ${ }^{58-60}$ in the field of metabolism and endocrinology challenge the traditional theory of bone resorption resulting only from estrogen deficiency in female athletes presenting menstrual disorders. Thus, it is suggested that not only estrogen deficiency but additionally nutritional deprivation and chronic energy deficit cause inadequate bone formation by altering the levels of various hormones affecting bone metabolism, such as insulin-like growth factor-1 (IGF-1), cortisol, leptin and ghrelin.

Specifically, IGF-1, an important factor for bone formation, ${ }^{58}$ is lower in adolescent athletes with amenorrhea in comparison to sedentary controls. ${ }^{59}$ Furthermore, intense physical stress and energy imbalance cause activation of the HPA axis and induce high cortisol levels, which unfavorably affect bone metabolism. ${ }^{60}$

In cell cultures, ghrelin exerted proliferative effects on osteoblasts, whereas studies on animal models indicated that leptin decreases bone mass. ${ }^{61}$ Christo 
et al reported higher ghrelin and lower leptin levels in amenorrheic adolescent athletes compared to eumenorrheic athletes and sedentary controls. ${ }^{62}$ This study showed bone age, lean mass, IGF-1 and estradiol, but not ghrelin and leptin, as important positive predictors of bone mass parameters. ${ }^{62}$ The involvement of leptin could provide a possible mechanism for an interaction between the nutritional status and bone metabolism, this suggesting a role for leptin as a physiologic regulator of bone mass. ${ }^{63}$ Thus, osteopenia characterizing amenorrheic women involved in aesthetics may represent another adaptive response to chronic undernutrition.

Many studies have documented lower bone mineral density in athletes with hypoestrogenic amenorrhea compared with regularly cycling athletes. ${ }^{64,65}$ Interestingly, Christo et al. compared bone density in adolescent amenorrheic vs eumenorrheic endurance athletes and non-athletic controls and found lower bone density at the spine, hip and whole body in adolescent amenorrheic athletes compared with the other two groups..$^{59}$ In this study, athletes with amenorrhea had significantly lower lumbar BMD $Z$-scores compared with athletes with eumenorrhea and control subjects. Lumbar BMD $Z$-scores $<-1$ were documented in $38 \%$ of athletes with amenorrhea compared with $16.7 \%$ of eumenorrheic athletes and $11 \%$ of sedentary controls.

BMD declines as the number of missed menstrual cycles increases and in such cases the loss of BMD may not be fully reversible. ${ }^{67}$ Stress fractures occur more commonly in physically active women with menstrual irregularities and/or low BMD with a relative risk for stress fracture two to four times greater in amenorrheic than eumenorrheic athletes. ${ }^{68}$ Studies involving ballet dancers have demonstrated higher prevalence of scoliosis and a greater incidence of delayed menarche among the dancers presenting scoliosis. ${ }^{69.70}$ These limited data, though implying a possible connection between idiopathic scoliosis and exercise-induced menstrual disorders, fail to provide convincing evidence of a common pathogenetic mechanism. The prevalence of stress fractures among dancers has been positively correlated with the duration of amenorrhea. ${ }^{71}$ Similarly, in runners the prevalence of stress fractures has been associated with the existence of menstrual disturbances. ${ }^{72}$

On the other hand, recent studies have highlighted the fact that weight-bearing exercise exerts a positive impact on bone density. Bembed et al. demonstrated that gymnasts were found to have significantly higher BMD compared with runners. ${ }^{73}$ In addition, Zanker et al studied retired gymnasts, competing in sports acrobatics during childhood and adolescence, and documented higher BMD in comparison with women who had never participated in structured sport or exercise. $^{74}$

Nichols et al studied female high-school athletes taking into account both the sport-specific type of mechanical loading and menstrual status. ${ }^{75}$ This study included eumenorrheic and amenorrheic female adolescents participating in high/odd impact sports (soccer, softball, volleyball, tennis, lacrosse, track sprinting and jumping) and repetitive/non-impact sports participants (swimmers, cross-country runners, track distance runners participating in events $\geq 800 \mathrm{~m}$ ). The data showed higher hip bone density in eumenorrheic high/odd impact athletes compared to eumenorrheic repetitive/non-impact athletes, as well as higher spine bone density in eumenorrheic high/ odd impact athletes compared with oligo/amenorrheic repetitive/non-impact athletes.

In Artistic Gymnastics, an increase in bone density was observed when related to bone age and not chronological age. ${ }^{76}$ Bone acquisition was proportional to the development of puberty according to Tanner stages of breast development and there was a strong negative influence of early onset of training on bone acquisition, indicating vulnerability of bone metabolism before the onset of sex steroids production. ${ }^{76}$ Therefore, the early exposure of AG to excess mechanical load exerts its beneficial effect on bone acquisition, after sex steroid production initiation leading to a positive net-effect. The same appears to be true of Rhythmic Gymnasts. ${ }^{77}$ Elite premenarcheal RG had significantly higher cortical BMD and cortical thickness compared to sedentary controls, indicating that Rhythmic Gymnastics in premenarcheal girls may induce positive adaptations on the skeleton, especially in cortical bone. ${ }^{77}$ 


\section{DETERMINING THE NEED FOR EVALUATION OF ATHLETES}

Evaluation is indicated in three clinical settings: (1) adolescents with primary amenorrhea (no menses by the age of 16) involved in strenuous exercise, (2) athletes at any age with secondary amenorrhea (previously menstruating) and (3) reproductively mature women undergoing intensive sport exercise and interested in conceiving.

\section{Diagnosis and evaluation}

The diagnosis of exercise-induced menstrual disorders remains a diagnosis by exclusion. The initial approach in evaluating athletes with reproductive dysfunction includes a full and thorough personal history with regard to menstrual patterns, pubertal development, dietary habits, weight changes, stressors, sexual activity, exercise history and family history. Finally, a complete physical examination should be carried out including breast and pubic hair inspection to determine the stage of maturity according to Tanner stages. Pelvic examination by sonography should also be performed.

The differential diagnosis includes possible underlying endocrinopathies, such as hyperprolactinemia and thyroid dysfunction, eating disorders and a physiologic postmenarcheal anovulatory state. The latter represents a self-limited period of anovulatory menstrual cycles occurring during the first year of menstruation, while additional cycles may be characterized by luteal phase deficiency. ${ }^{8}$ Pregnancy should always be ruled out in sexually active athletes. Furthermore, less common causes of amenorrhea should be excluded, such as Müllerian abnormalities, gonadal dysgenesis and androgen insensitivity syndrome.

Laboratory studies include determination of serum follicle-stimulating hormone ( $\mathrm{FSH}), \mathrm{LH}$, prolactin, thyroid-stimulating hormone (TSH), b-human chorionic gonadotropin ( $\beta$-hCG) (the latter to exclude pregnancy) testosterone, dehydroepiandrosterone sulfate (DHEA-S), estrogens and possibly a progestin challenge. Magnetic resonance imaging (MRI) of the hypothalamic-pituitary area is the examination of choice in the presence of hyperprolactinemia.

Essential for the assessment of maturation and pubertal development is the determination of bone age, as pubertal progression and bone mass acquisition follow bone age rather than chronological age. ${ }^{78}$ Bone age is commonly evaluated via an $\mathrm{x}$-ray of left hand and wrist.

In cases of secondary amenorrhea, estrogen status should be evaluated by determining serum estradiol (E2) levels and/or via a progestin withdrawal test: in the presence of estrogen action, endometrial lining is developed, progesterone action maintains the endometrial lining and its withdrawal induces bleeding. A negative progestin withdrawal test or levels of estradiol lower than $60 \mathrm{pg} / \mathrm{ml}$ (critical level for maintaining bone density) reflect the severity of potential osteopenia. ${ }^{79}$

\section{THERAPEUTIC INTERVENTIONS}

The aim of intervention is to control short-term symptoms such as irregular bleeding, and to prevent long-term effects such as osteoporosis. The management options for treatment of menstrual disorders in athletes include behavioral changes, improved dietary habits, re-evaluation of the intensity and duration of training as well as pharmacologic intervention. In general, treatment should be individualized taking into account age, risk factors and the severity of the reproductive dysfunction and its consequences.

The most severely affected athletes who will require aggressive management are amenorrheic women with current evidence of osteopenia/osteoporosis. Initially, the athlete is prompted to modify diet and exercise behaviour. These modifications aim at improving energy availability by increasing energy intake and reducing energy expenditure, or a combination, according to the athlete's compliance with recommendations. ${ }^{80}$

Reducing the level of exercise can produce dramatic changes in menstrual function. ${ }^{81}$ Furthermore, menstrual cycles may be restored by increasing energy intake to more than $30 \mathrm{kcal}$ per $\mathrm{kg}$ of free fat mass (FFM) daily. The strong association between increases in BMD and increases in body weight implies that increasing BMD may require more than $45 \mathrm{kcal}$ per $\mathrm{kg}$ of FFM daily. This value corresponds to energy balance in healthy young women. ${ }^{81}$

With regard to dietary and nutritional aspects, a 
recent two-year prospective cohort study of young female runners, based on a food frequency questionnaire, showed that low-fat dairy products, potassium and the major nutrients in milk (calcium, vitamin $\mathrm{D}$ and protein) are positively associated with bone gains and a lower stress fracture rate. ${ }^{82}$ Thus, adequate amounts of bone-building nutrients should be prescribed, including calcium $>1200 \mathrm{mg} /$ day and vitamin D $800 \mathrm{IU} /$ day.

Initiation of pharmacologic treatment should be considered in the case of athletes unwilling to follow dietary interventions or modify the exercise regimen, or athletes who, despite their compliance with nutritional counselling, fail to achieve restoration of menstrual function after a period of 6 months. In any case, the decision for pharmacologic treatment should be individualized, based on chronological age, bone density and bone loss.

The most commonly prescribed treatment for young amenorrheic women with bone loss is hormone replacement therapy (HRT) and oral contraceptives (OC). Hormone replacement therapy, consisting of cyclic estrogen administration in combination with progestin, establishes preservation of bone mass and provides regular bleeding at predictable times. This regimen will prevent or relieve atrophic vaginitis and urethritis but will not provide contraception. Sideeffects, which are uncommon, include depression, lethargy and bloating on the days of progestin ingestion, while very few women, previously hypoestrogenic, report mild fluid retention and weight gain. It must however be stressed that preparations containing high concentrations of estrogen raise concern about thromboembolic episodes.

There are many preparations available providing systemic, oral and transdermal estrogen administration, while newly developed products introduce percutaneous estradiol and transvaginal progesterone administration. ${ }^{83}$ Several studies have been published comparing oral with transdermal estrogen administration with specific regard to respective safety and efficacy.

Administration of oral estrogens leads to suppression of both baseline and growth-hormone stimulated insulin-like growth factor I (IGF-I) concentrations, while transdermal estrogen did not have a negative ef- fect on IGF-I ${ }^{84}$ Moreover, studies on postmenopausal women on transdermal HRT suggest a moderately beneficial influence on body composition, inflammatory markers and cardiovascular parameters.$^{83}$ Finally, Hemelaar et al underscore the relatively safer profile of oral HRT in relation to atherosclerotic and venous thromboembolic disease. ${ }^{85}$ Hemelaar's conclusions are based on a review of studies comparing non-oral with oral postmenopausal HRT.

On the other hand, though OC administration side-effects are more common compared with those of HRT, they are limited to headache, nausea, breast tenderness and weight gain and, less commonly, infrequent and mild breakthrough bleeding and amenorrhea. These side-effects are of major clinical importance because they often lead to discontinuation of treatment. Regarding the adolescent female younger than 16 years of age with functional hypothalamic amenorrhea, there are no established guidelines as to whether or when to administer OC due to concern for premature closure of growth plates as well as lack of research to support such therapy in this age group.

Even though commonly and widely used, the influence of HRT or OC treatment on bone mass in hypoestrogenic amenorrheic athletes remains controversial. Very few prospective data exist to aid clinicians in making evidence-based decisions as to the optimal treatment regimens.

HRT may prevent further loss of bone in athletes with amenorrhea of recent onset but will not replace all the bone loss that has occurred in cases of longer lasting amenorrhea ${ }^{86}$ A longitudinal study documented minimal bone accretion following a 2-year HRT compared with the BMD increase following spontaneous reversal of amenorrhea in a cohort of ballet dancers. ${ }^{87}$ Moreover, Liu and Lebrun reviewed studies on the efficacy of estrogen therapy in hypothalamic amenorrhea and concluded that there is limited evidence to support a positive effect of such intervention on BMD. ${ }^{88}$

Oral contraceptives will probably maintain bone density in hypoestrogenic, amenorrheic athletes while additionally providing contraception. Furthermore, recent studies demonstrated that the estrogen component in $\mathrm{OC}$ exerts a protective role on endothelial 
function, reducing the cardiovascular risk in amenorrheic athletes. ${ }^{89}$ Cobb et al. conducted a randomized trial to test the effect of $\mathrm{OC}$ use on bone mass and stress fracture incidence in female runners..$^{90}$ This study involving 150 competitive female runners, randomly assigned to OC ( $30 \mu \mathrm{g}$ of ethinyl estradiol and $0.3 \mathrm{mg}$ of norgestrel) or control (no intervention) for a period of two years, failed to reach conclusive results. Lastly, a systematic review published in 2008 and collecting all studies regarding management strategies to reverse bone loss in women with functional hypothalamic amenorrhea concluded that no pharmacologic treatment had a noteworthy effect on BMD increase, other than bone mass preservation. ${ }^{91}$

There has lately been growing interest in the use of low-dose oral contraceptives. Existing studies on healthy adolescents and women with hypothalamic amenorrhea underscore their safety and contraceptive efficacy. ${ }^{92,93}$ Martins et al. reviewed published data on the influence of combined hormonal contraception on bone health and reported that adolescents and young women who use low-dose and very low-dose OC have lower BMD than controls. ${ }^{94}$ Among the few data concerning exercise and athletes, a recent study concluded that the use of low dose OC (containing $0.20 \mathrm{mg}$ of ethinyl estradiol plus $0.15 \mathrm{mg}$ of gestogen) had no effect on peak aerobic capacity and the anaerobic threshold level. ${ }^{95}$ Furthermore, a study of a small cohort of endurance athletes with menstrual disorders treated with low dose OC suggested that $\mathrm{OC}$ treatment increases body fat mass and improves metabolic balance..$^{96}$

The central role of leptin in the pathophysiology of exercise-related menstrual disorders has introduced novel approaches in the management of athletic amenorrhea. Exogenous leptin (recombinant r-metHuLeptin) administration managed to improve the reproductive function of a small cohort of women with hypothalamic amenorrhea caused by strenuous exercise or low weight, suggesting a possible therapeutic role. ${ }^{97}$

Other pharmacologic agents approved for treatment of post-menopausal osteoporosis such as biphosphonates should not be used in the management of bone pathology in athletes with amenorrhea, since these agents have not been studied in young women.
Moreover, they may reside in the skeleton for many years, exerting a potential effect on a developing fetus during pregnancy. Bachrach reviewed the literature on the use of bisphosphonates in children and confirmed the lack of convincing evidence on aspects of safety and efficacy. ${ }^{98}$

Finally, it is to be noted that there are athletes, mainly at the high competitive level, who refuse or discontinue the recommended therapy. These individuals, who are accustomed to amenorrhea, are concerned about the effect of the resumption of menses or the administered therapy on their performance. It must be mentioned, however, that there are no data to document or suggest any adverse effect of menstruation, HRT or OC use on physical performance. ${ }^{99}$

\section{CONCLUSION}

Intensive physical training may lead to detrimental effects on physical health. Low energy intake combined with increased energy expenditure can result in reproductive dysfunction. Exercise-related reproductive disorders have been shown to have serious consequences, mainly involving osteoporosis. Thus, preventive measures, prompt evaluation and management of individuals at risk are highly recommended.

\section{REFERENCES}

1. Warren MP, Perlroth NE, 2001 The effects of intense exercise on the female reproductive system. J Endocrinol 170: 3-11

2. Erladson MC, Sherar LB, Milwald RL, Miffulli N, BaxterJones AD, 2008 Growth and maturation of adolescent female gymnasts, swimmers, and tennis players. Med Sci Sports Exerc 40: 34-42.

3. Warren MP, 1980 The effects of exercise on pubertal progression and reproductive function in girls. J Clin Endocrinol Metab 51: 1150-1157.

4. Marcus R, Cann C, Madvij P, et al, 1985 Menstrual function and bone mass in elite women distance runners. Ann Intern Med 102: 158-163.

5. Baxter-Jones ADG, Helms P, Baines-Preece J, Preece M, 1994 Menarche in intensively trained gymnasts, swimmers and tennis players. Ann Hum Biol 21: 407-415.

6. Peltenburg AL, Erich WBM, Bernink MJE, Zonderland ML, Huisveld IA, 1984 Biological maturation, body composition and growth of female gymnasts and control groups of schoolgirls and girls swimmers, aged 8 to 14 years: a cross-sectional survey of 1064 girls. Int J Sports Med 5: 36-42. 
7. Torstveit MK, Sundgot-Borgen J, 2005 Participation in leanness sports but not training volume is associated with menstrual dysfunction: A national survey of 1276 elite athletes and controls. British Journal of Sports Medicine 39: 141-147.

8. Loucks AB, Mortola JSF, Girton L, et al, 1989 Alterations in the hypothalamic-pituitary-ovarian and the hypothalamic-pituitary-adrenal axis in athletic women. J Clin Endocrinol Metab 68: 402-411.

9. Redman LM, Loucks AB, 2005 Menstrual disorders in athletes. Sports Medicine 35): 747-755.

10. Frisch RE, McArthur JW, 1974 Menstrual cycles; Fatness as a determinant of minimum weight for height necessary for their maintenance or onset. Science 185: 949-995.

11. Trussel J, 1980 Statistical flaws in evidence for the Frisch hypothesis that fatness triggers menarche. Hum Biol 52: 711-720.

12. Bronson FH, Manning JM, 1991 The energetic regulation of ovulation: a realistic role for body fat. Biol Reprod 44: 945-950.

13. Loucks AB, 2003 Energy availability, not body fatness, regulates reproductive function in women. Exercise and Sport Sciences Reviews 31: 144-148.

14. Moschos S, Chen JL, Mantzoros CS, 2002 Leptin and reproduction; a review. Fertil Steril 77: 433-444.

15. Miller KK, Grinspon S, Gleysteen S, et al, 2004 Preservation of neuroendocrine control of reproductive function, despite severe undernutrition. J Clin Endocrinol Metab 89: 4434-4438.

16. Köpp W, Blum WF, von Prittwitz S, et al, 1997 Low leptin levels predict amenorrhea in underweight and eating disordered females. Mol Psychiatry 2: 335-340.

17. Launhlin GA, Yen SSC, 1997 Hypoleptinemia in women athletes: absence of diurnal rhythm with amenorrhea. J Clin Endocrinol Metab 82: 318-321.

18. Rodriguez-Pacheco F, Martinez-Fuentes AJ, Tovar S, et al, 2007 Regulation of pituitary cell function by adiponectin. Endocrinology 148: 401-410.

19. Lu M, Tang Q, Olefsky JM, Mellon PL, Webster NJ, 2008 Adiponectin activates adenosine monophosphate activated protein kinase and decreases luteinizing hormone secretion in LbetaT2 gonadotropes. Mol Endocrinol 22: 760-771.

20. Selye H, 1939 The effect of adaptation to various damaging agents on the female sex organs in the rats. Endocrinology 25: 615-624.

21. Chen MD, O'Byrne KT, Chiappini SE, Hotchkiss J, Knobil E, 1992 Hypoglycemic stress and the gonadotrophin- releasing hormone pulse generator activity in the rhesus monkey: the role of the ovary. Neuroendocrinology 56: 666-673.

22. Chrousos GP, Torpy DJ, Gold PW, 1998 Interactions between the Hypothalamic-Pituitary-Adrenal Axis and the Female Reproductive System: Clinical Implications. Ann Intern Med 129: 229-240.

23. Bullen BA, Skrinar GS, Beitins IZ, et al, 1985 Induction of menstrual disorders by strenuous exercise in untrained women. N Engl J Med 312: 1349-1353.

24. Laughlin GA, Yen SSC, 1996 Nutritional and endocrinemetabolic aberrations in amenorrheic athletes. J Clin Endocrinol Metab 81: 4301-4309.

25. Ding JH, Schecter CB, Drinkwater BL, 1988 High serum cortisol levels in exercise associated amenorrhea. Ann Intern Med 108: 530-534.

26. Gindoff PR, Ferin M, 1987 Endogenous opioid peptides modulate the effect of corticotrophin-releasing factor on gonadotrophin release in the primate. Endocrinology 121: 837-842.

27. Marcus MD, Loucks TL, Berga SL, 2001 Psychological correlates of functional hypothalamic amenorrhea. Fertil Steril 76: 310-316.

28. Schwartz B, Cummings DC, Riordan E, Selye M, Yen SSC, Rebar RW, 1981 Exercise associated amenorrhea: a distinct entity? Am J Obstet Gynecol 141: 662-670.

29. Williams NI, Helmreichch DL, Parfitt DB, CastonBalderrama AL, Cameron JL, 2001 Evidence for a causal role of low energy availability in the induction of menstrual cycle disturbances during strenuous exercise training. J Clin Endocrinol Metab 86: 5184-5193.

30. Loucks AB, Verdun M, Heath EM, 1998 Low energy availability, not stress of exercise, alters LH pulsatility in exercising women. J Appl Physiol 84: 37-46.

31. Pirke KM, Schweiger V, Laessle R, Dickhaut B, Schweiger M, Waechtler M, 1986 Dieting influences the menstrual cycle: vegetarian versus nonvegetarian diet. Fertil Steril 46: 1083-1088.

32. Barr SI, Janelle KC, Prior JC, 1994 Vegetarian vs nonvegetarian diets, dietary restraint, and subclinical ovulatory disturbances: prospective 6-mo study. Am J Clin Nutr 60: 887-894.

33. De Souza MJ, Metzger DA, 1991 Reproductive dysfunction in amenorrheic athletes and anorexic patients: a review. Med Sci Sports Exerc 23: 995-1007.

34. Rogol AD, Weltman JY, Seip RL, et al, 1992 Durability of the reproductive axis in eumenorrheic women during one year of endurance training. J Appl Physiol 72: 1571-1580.

35. Frisch RE, Wyshak G, Vincent L, 1980 Delayed menarche and amenorrhea in ballet dancers. N Engl J Med 303: 17-19.

36. Sanborn CF, Martin BJ, Wagner WW, 1982 Is athletic amenorrhea specific to runners? Am J Obstet Gynecol 143: 859-861.

37. Bonen A, 1992 Recreational exercise does not impair menstrual cycles: a prospective study. Int J Sports Med 13: $110-120$.

38. Rosetta L, 1993 Female reproductive dysfunction and intense physical training. Oxf Rev Reprod Biol 15: 113-141.

39. Bennell KL, Malcolm SA, Khan KM, et al, 1997 Bone mass and bone turnover in power athletes, endurance athletes, and controls. A 12 month longitudinal study. Bone 20: 477-484.

40. Sanborn CF, Albrecht BH, Wagner WW Jr, 1987 Athletic 
amenorrhea: lack of association with body fat. Medicine and Science in Sports and Exercise 19: 207-212.

41. Shangold MM, Levine HS, 1982 The effect of marathon training upon menstrual function. Am J Obstet Gynecol 143: 862-869.

42. De Souza MJ, Miler BE, Loucks AB, et al, 1998 High frequency of luteal phase deficiency and anovulation in recreational women runners: blunted elevation in folliclestimulating hormone observed during luteal-follicular transition. J Clin Endocrinol Metab 83: 4220-4232.

43. Lucas JA, Lucas PR, Vogel S, et al, 2003 Effect of sub-elite competitive running on bone density, body composition and sexual maturity of adolescents females. Osteoporos Int 14: 848-856.

44. Constantini NW, Warren MP, 1995 Menstrual dysfunction in swimmers: A distinct entity. J Clin Endocrinol Metab 80: 2740-2744.

45. Claessens A, Lefevre J, Beunen G, Malina RM, 1999 The contribution of anthropometric characteristics to performance scores in elite female gymnasts. J Sports Med Phys Fitness 39: 355-360.

46. Georgopoulos NA, Markou K, Theodoropoulou A, et al, 1999 Growth and pubertal development in elite female rhythmic gymnasts. J Clin Endocrinol Metab 84: 4525-4530.

47. Georgopoulos NA, Markou K, Theodoropoulou A, et al, 2001 Height velocity and skeletal maturation in elite female rhythmic gymnasts. J Clin Endocrinol Metab 86: 5159-5164.

48. Theodoropoulou A, Markou K, Vagenakis GA, et al, 2005 Delayed but Normally Progressed Puberty Is More Pronounced in Artistic Compared with Rhythmic Elite Gymnasts Due to the Intensity of Training. J Clin Endocrinol Metab 90: 6022-6027.

49. Georgopoulos NA, Markou KB, Theodoropoulou A, Benardot D, Leglise M, Vagenakis AG, 2002 Growth Retardation in Artistic Compared to Rhythmic Elite Female Gymnasts. J Clin Endocrinol. Metab 87: 3169-3173.

50. Tanner JM, Whitehous RH, Marsall WA, Carter BS, 1975 Prediction of adult height, bone age, and occurrence of menarche, at age 4 to 16 with allowance for midparental height. Arc Dis Child 50: 14-26.

51. Georgopoulos NA, Theodoropoulou A, Leglise M, Vagenakis AG, Markou K, 2004 Growth and Skeletal Maturation in male and female Artistic Gymnasts. J Clin Endocrinol Metab 89: 4377-4382.

52. Marshall WA, Tanner JM, 1969 Variations in pattern of pubertal changes in girls. Arch Dis Child 44: 291-303.

53. Hoch AZ, Dempsey RL, Carrera GF, et al, 2003 Is endothelial dysfunction between athletic amenorrhea and endothelial cell dysfunction? Med Sci Sports Exerc 35: 377-383.

54. Rickenlund A, Eriksson MJ, Schenck-Gustafsson K, Hirschberg AL, 2005 Amenorrhea in female athletes is associated with endothelial dysfunction and unfavorable lipid profile. J Clin Endocrinol Metab 90: 1354-1359.

55. De Souza MJ, West SL, Jamal SA, et al, 2008 The pres- ence of both an energy deficiency and estrogen deficiency exacerbate alterations of bone metabolism in exercising women. Bone 43:140-148.

56. Marcus R 1996 Mechanisms of exercise effects on bone. In: Bilezikian JP, Raaaaisz LG, Rodan GA Principles of Bone Biology ( $1^{\text {st }}$ edition$)$, San Diego CA Academic Press pp; 1135-1146.

57. Katzman DK, Bachrach LK, Carter DR, Marcus R, 1991 Clinical and anthropometric correlates of bone mineral acquisition in healthy adolescent girls. J Clin Endocrinol Metab 73: 1332-1339.

58. Fehily AM, Coles RJ, Evans WD, et al, 1992 Factors affecting bone density in young adults. Am. J Clin Nutr 56: 579-586.

59. Christo K, Prabhakaran R, Lamparello B, et al, 2008 Bone Metabolism in Adolescent Athletes With Amenorrhea, Athletes With Eumenorrhea and Control Subjects. Pediatrics 121: 1127-1136.

60. Abad V, Chrousos G, Reynolds J, et al, 2001 Glucocorticoid excess during adolescence leads to a major persistent deficit in bone mass and an increase in central body fat. J Bone Miner Res 16: 1879-1885.

61. Misra M, 2008 Bone density in the adolescent athlete. Rev Endocr Metab Disord 9: 139-144.

62. Christo K, Cord J, Mendes N, et al, 2008 Acylated ghrelin and leptin in adolescent athletes with amenorrhea, eumenorrheic athletes and controls: a cross sectional study. Clin Endocrinol (Oxf) 69: 628-633.

63. Miller KK, Parulekar MS, Schoenfeld E, et al, 1998 Decreased leptin levels in normal weight women with hypothalamic amenorrhea: the effects of body composition and nutritional intake. J Clin Endocrinol Metab 83: 2309-2312.

64. Drinkwater BL, Nilson K, Chesnut CH III, Bremner WJ, Shainholtz S, Southworth MB, 1984 Bone mineral content of amenorrheic and eumenorrheic athletes. N Engl J Med 311: 277-281.

65. Marcus R, Cann CE, Madvig P, et al, 1985 Menstrual function and bone mass in elite women distance runners. Annals of Internal Medicine 102: 158-163.

66. Drinkwater BL, Bruemner B, Chesnut CH III, 1990 Menstrual history as a determinant of current bone density in young athletes. JAMA 263: 545-548.

67. Keen AD, Drinkwater BL, 1997 Irreversible bone loss in former amenorrheic athletes. Osteoporos Int 7: 311-315.

68. Warren MP, Brooks-Gunn J, Fox RP, Holderness CC, Hyle EP, Hamilton WG, 2002 Osteopenia in exercise associated amenorrhea using ballet dancers as a model: a longitudinal study. J Clin Endocrinol Metab 87: 31623168 .

69. Warren MP, Brooks-Gunn J, Hamilton LH, 1986 Scoliosis and fractures in young ballet dancers. Relation to delayed menarche and secondary amenorrhea. N Engl J Med 314: 1348-1353.

70. Kenanidis E, Potoupnis ME, Papavasiliou KA, Sayegh FE, Kapetanos GA 2008 Adolescent idiopathic scoliosis and exercising: Is there truly a liaison? Spine 33: 
2160-2165.

71. Myburgh KH, Hutchins J, Fataar AB, Hough SF, Noakes TD, 1990 Low bone density is an etiologic factor for stress fractures in athletes. Annals of Internal Medicine 113: 754-759.

72. Warren MP, Brooks-Gunn J, Hamilton LH, Warren LF, Hamilton WG 1986 Scoliosis and fractures in young ballet dancers: relation to delayed menarche and secondary amenorrhea. N Engl J Med 314: 1348-1353.

73. Bemben DA, Buchanan TD, Bemben MG, Knehans AW, 2004 Influence of type of mechanical loading, menstrual status and training season on bone density in young women athletes. J Strength Cond Res 18: 220-226.

74. Zanker CL, Osborne C, Cooke CB, Oldroyd B, Truscott JG, 2004 Energy balance, bone turnover and menstrual history of sedentary female former gymnasts, aged 20-32 years. Osteoporosis Int 15: 145-154.

75. Nichols JF, Rauh MJ, Barrack MT, Barkai HS, 2007 Bone mineral density in female high school athletes: interactions of menstrual function and type of mechanical loading. Bone 41: 371-377.

76. Markou KB, Mylonas P, Theodoropoulou A, et al, 2004 The Influence of Intensive Physical Exercise on Bone Acquisition in Adolescent Elite Female and Male Artistic Gymnasts. J Clin Endocrinol Metab 89: 4383-4387.

77. Tournis S, Michopoulou E, Fatouros IG, et al, 2010 Effect of Rhythmic Gymnastics on Volumetric Bone Mineral Density and Bone Geometry in Premenarcheal Female Athletes and Controls. J Clin Endocrinol Metab 2010 Apr 7. [Epub ahead of print].

78. Shangold M, Rebar RW, Colston Wetz A, Schiff I, 1990 Evaluation and management of menstrual dysfunction in athletes. J Amer Med Assoc 263: 1665-1669.

79. Dueck CA, Matt KS, Manore MM, Skinner JS, 1996 Treatment of athletic amenorrhea with a diet and training intervention program. Int J Sport Nutr 6: 24-40.

80. Loucks AB, 1990 Effects of exercise training on the menstrual cycle: existence and mechanisms. Med Sci Sports Exerc 22: 275-280.

81. Goodman LR, Warren MP, 2005 The female athlete and menstrual function. Curr Opin Obstet Gynecol 17: 466-470.

82. Nieves JW, Melsop K, Curtis M, et al, 2010 Nutritional factors that influence change in bone density and stress fracture risk among young female cross-country runners. PM R 2: 740-750.

83. Divasta AD, Gordon CM, 2010 Hormone replacement therapy and the adolescent. Curr Opin Obstet Gynecol 22: 363-368.

84. Lissett CA, Shalet SM, 2003 The impact of dose and route of estrogen administration on the somatotropic axis in normal women. J Clin Endocrinol Metab 88: 4668-4672.

85. Hemelaar M, van der Mooren MJ, Rad M, Kluft C, Kenemans P, 2008 Effects of non-oral postmenopausal hormone therapy on markers of cardiovascular risk: A systematic review. Fertil Steril 90: 642-672.

86. Goodman LR, Warren MP, 2005 The female athlete and menstrual function. Curr Opin Obstet Gynecol 17: 466-470.

87. Warren MP, Brooks-Gunn J, Fox RP, et al, 2003 Persistent osteopenia in ballet dancers with amenorrhea and delayed menarche despite hormone therapy: a longitudinal study. Fertil Steril 80: 398-404.

88. Liu SL, Lebrun CM, 2006 Effect of oral contraceptives and hormone replacement therapy on bone mineral density in premenopausal and perimenopausal women: a systematic review. Br J Sports Med 40: 11-24.

89. Rickenlund A, Eriksson MJ, Schenck-Gustafsson K, Hirschberg AL, 2005 Oral contraceptives improve endothelial function in amenorrheic Athletes J Clin Endocrinol Metab, 90: 3162-3167

90. Cobb KL, Bachrach LK, Sowers M, et al, 2007 The effect of oral contraceptives on bone mass and stress fractures in female runners. Med Sci Sports Exerc 39: 1464-1473.

91. Vescovi JD, Jamal SA, De Souza MJ, 2008 Strategies to reverse bone loss in women with functional hypothalamic amenorrhea: a systematic review of the literature. Osteoporos Int 19: 465-478.

92. Poindexter A, 2001 The emerging use of the $20-\mu \mathrm{g}$ oral contraceptive. Fertil Steril 75: 457-465.

93. Warren MP, Miller KK, Olson WH, Grinspoon SK, Friedman AJ, 2005 Effects of an oral contraceptive (norgestimate/ethinyl estradiol) on bone mineral density in women with hypothalamic amenorrhea and osteopenia: an open-label extension of a double-blind, placebocontrolled study. Contraception 72: 206-211.

94. Martins SL, Curtis KM, Glasier AF, 2006 Combined hormonal contraception and bone health: a systematic review. Contraception 73: 445- 469.

95. Rebelo AC, Zuttin RS, Verlengia R, Cesar Mde C, de Sá MF, da Silva E, 2010 Effect of low-dose combined oral contraceptive on aerobic capacity and anaerobic threshold level in active and sedentary young women. Contraception 81: 309-315.

96. Rickenlund A, Thoren M, Nybacka A, Frystyk J, Hirschberg AL, 2010 Effects of oral contraceptives on diurnal profiles of insulin, insulin-like growth factor binding protein-1, growth hormone and cortisol in endurance athletes with menstrual disturbance. Human Reproduction 25: 85-93.

97. Welt CK, Chan JL, Bullen J, et al, 2004 Recombinant Human Leptin in Women with Hypothalamic Amenorrhea. N Engl J Med 351: 987-997.

98. Bachrach LK, Ward LM, 2009 Clinical review 1: Bisphosphonate use in childhood osteoporosis. J Clin Endocrinol Metab 94: 400-409.

99. Lebrun CM, 1994 The effect of the phase of the menstrual cycle and the birth control pill on athletic performance. Clin Sports Med 13: 419-441. 